\title{
"Eros ferido": teoria e tradução do Idílio XIX de Teócrito de Siracusa
}

Daniel Padilha Pacheco da Costa

\begin{abstract}
Resumo: No artigo, realizamos uma tradução em verso do idílio XIX do poeta belenístico Teócrito de Siracusa. Discutimos não apenas o sentido e a estrutura do poema, mas também o seu lugar no interior da sua obra e as traduções que recebeu em Portugal e em português. Mais curto idílio de Teócrito, a anedota sobre a infância de Eros narrada no poema é representativa do privilégio dado pela poesia helenistica a poemas breves. Por fim, explicitamos os critérios que nortearam a tradução, entendida não como uma somatória de elementos linguísticos, mas como uma totalidade coerente com o modelo.
\end{abstract}

Palavras-chave: Teócrito; Idilio XIX; história da tradução; poesia helenística. anedota sobre Eros.

Omnia vincit amor et nos cedamus amori!

(Vergilius, 1998)

\section{O idílio XIX}

Os idílios atribuídos a Teócrito de Siracusa (século III a.C. Ápice: c. 270 a.C) - um dos três maiores e mais famosos poetas do período helenístico das letras gregas ao lado de Apolônio de Rodes e Calímaco de Cirene - são comumente associados ao gênero pastoril. $\mathrm{O}$ fato se deve em grande medida à importância que as Éclogas de Virgílio, que imitam a poesia pastoril helenística, em geral, e Teócrito, em particular, adquiriram entre os gêneros poéticos das literaturas vernáculas europeias. Com efeito, para ser breve, as Éclogas se tornaram modelo poético imitado no século XIV por poetas como Dante e Petrarca na Itália e no século XV por Sá de Miranda, Bernardim Ribeiro e Camões em Portugal. Graças a isso, Teócrito recebeu as primeiras traduções portuguesas já no século XVI, embora 
tenha sido preciso esperar a primeira metade do século XX para que seus idílios pastoris se tornassem objeto de um número significativo de traduções em nossa língua (RODRIGUES, 2000).

Embora os tradutores em língua portuguesa tenham privilegiado a vertente bucólica, os idílios de Teócrito incluem e acolhem em si grande variedade de outros gêneros poéticos. Entre seus 31 idílios, podemos encontrar mimos, encômios, hinos, priapéias, além de bucólicas. Também lhe são atribuídos 24 epigramas transmitidos pela Antologia Palatina. Segundo o preceito da poikiliá ${ }^{1}$ - isto é, da combinação de gêneros - também praticada por outros poetas helenísticos, como Calímaco por exemplo -, Teócrito serviu-se de diferentes metros, temas e dialetos. Para chamar a atenção para a variedade dessa poesia, optamos por traduzir em língua portuguesa o idílio XIX, que é singularíssimo por acolher a anedota, espécie da historiografia antiga.

À parte os epigramas, o idílio XIX é a composição mais breve de Teócrito e, como tal, representativa do apreço que a poesia helenística calimaquiana de-

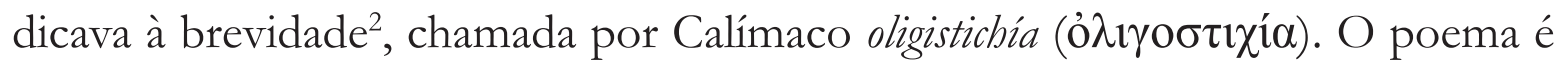
inteiramente composto em hexâmetros dactílicos, verso preferido do poeta, que também o utilizou nos poemas bucólicos. Como o hexâmetro dactílico é o metro da Ilíada e da Odisseia, sua utilização por Teócrito permite contrastar a brevidade da narrativa do idílio XIX com o fôlego da épica homérica. O contraste é tanto mais significativo, se considerarmos que, tal como as epopéias de Homero, o idílio também põe em cena divindades.

O idílio XIX acabou por receber o título "Ladrão de Mel", porque narra a picada que o menino Eros levou de uma abelha quando roubava mel da colméia. Depois de espernear de dor, o deus menino reclama com a mãe, Afrodite, pela dor causada por um animal tão pequeno. Ela ri da cena irônica em que Eros, que "tudo vence", como afirma Virgílio (1835, p. 193) na última bucólica, é vítima de uma abelha. Considerando não apenas a brevidade, mas o desfecho cômico, o idílio pode ser considerado uma "anedota". Como disse, esse gênero breve narra um episódio relacionado à vida de uma personagem, entendendo-se "vida", bíos

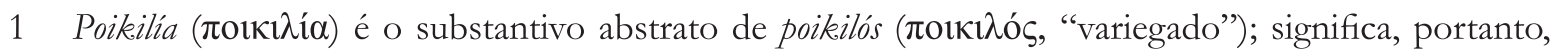
"variegação", "matização", como qualidade originariamente atribuída à cor, depois ao som, e tecnicamente, como termo de poética, à matização que um poema ganha por combinar mais de um gênero poético.

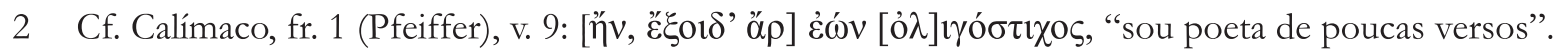
Assim como em poikiliáa, A qualidade, tomada como conceito, é a oligistichía (ỏ $\lambda \imath \gamma o \sigma \tau \imath \chi i ́ \alpha)$, como se lê na

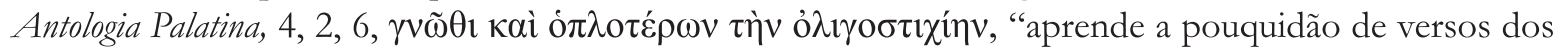
poetas de hoje". 
(Bios), isto é, a "biografia", como espécie da historiografia antiga. A anedota narrada no idílio XIX sobre a infância de Eros mostra um deus, personagem elevada, a desempenhar ação ridícula, roubar mel e ser aferroado por uma abelha.

Com base nas concepções modernas de poesia como "expressão" e de autor como "criador da obra" e "garantia de autenticidade", a autoria de alguns idílios de Teócrito foi rejeitada por editores a partir do século XIX (THÉOCRITE, 1931, p. 5). Nosso poema faz parte desse grupo, como afirma GOW: "Admite-se via de regra que o idílio XIX não pode de ser de Teócrito" (THEOCRITUS, 1973, p. 362). O helenista francês P.-E. Legrand nem sequer o inclui em sua edição e tradução da poesia de Teócrito (THÉOCRITE, 2002). Não cabe aqui discutir a complexa questão da autoria dos Idílios, mas nos limitamos a assinalar que o idílio XIX foi transmitido sob a "autoridade" (auctoritas) de Teócrito por alguns manuscritos.

\section{História concisa do Idílio XIX em Portugal e em português}

O poema foi traduzido em latim no século XVI por Antônio de Gouveia, que o intitulou "Amor ferido" (Ictus Amor). Assimilando-o aos epigramas de Teócrito, Gouveia transformou os oito hexâmetros originais num epigrama composto de dísticos elegíacos:

\section{ICTUS AMOR E GRAECO THEOCRITI ${ }^{4}$}

Mella Puer Veneris legeret cum forte, legenti

Extremos digitos noxia fixit apis.

Exclamat, terramque ferit, flatuque dolorem

Frigidulo ignitum uincere temptat Amor.

Sic gemebundus adit Venerem, cui, respice, dixit,

Magna perexiguae uulnera, Matcr, apis.

Cui Mater, "Tibi uis est, Nate, simillima: namque

Exigua infligis uulnera saeua manu".

Esse epigrama latino de Antônio Gouveia recebeu duas traduções em português por Ricardo Cunha Lima (2010), uma em decassílabos, outra em dísti-

3 "It is generally agreed that it cannot be by Theocritus."

4 In: Ricardo da Cunha Lima (2010, p. 68). 
cos de alexandrinos com decassílabos, publicadas no número 11 destes Cadernos de Literatura em Tradução. Assim, as traduções que Ricardo Cunha Lima fez do epigrama de Gouveia constituem, elas mesmas, traduções de uma tradução do idílio XIX de Teócrito.

Mas o próprio poema de Teócrito já tinha recebido duas traduções portuguesas e nada indica que sejam diretas. Uma é do século XVIII:

"O Ladrão de Mel ou o Ladrão dos Favos (Do Amor Mordido de uma Abelha)"

De uma abelha o Amor na mão mordido,

Chorando a Mãi se foi todo e espantado

De ser de tão pequena ave ferido,

E ficar da ferida tão cortado;

Vénus, vendo o menino assim corrido,

E da dor grande e nova tão tornado ${ }^{6}$,

Lhe disse: «Deixa os choros, e os espantos,

"Que tambem és pequeno, e feres tantos".

A outra tradução, muito expandida, é do século XVIII, mas publicada no século $\mathrm{XIX}^{7}$
Amor formigueiro 8
Por acaso hum dia
De doces colmêas
Os favos colhia.

5 In: Nuno Simão Rodrigues (p. 137), que anota: “Tradução do Idílio XIX de Pseudo-Teócríto, ‘O Ladrão de Mel', feita por Pedro de Andrade Caminha em Poesias, publicada pela Academia Real das Ciências em 1791, p. 303. O texto é apresentado com um titulo que não corresponde ao atribuído pelos helenistas: 'Do Amor Mordido de uma Abelha"'.

6 Tornado: transformado. O sentido é "tão transformado pela grande e nova dor".

7 In: Nuno Simão Rodrigues (p. 139), que anota “Tradução do Idílio XIX de Pseudo-Teócrito,'O Ladrão de Mel', feita por um Anónimo (M. P. T. P. e A.) e publicada no Jardim das Musas e dos Sábios, Ramalhete V, Lisboa, Impressão Regia, 1805, pp. 77-78”. Graças ao livro de Adriano da Guerra Andrade (p. 178), podemos informar que o tradutor é Manuel Pedro Tomás Pinheiro e Aragão.

8 Formigueiro: é adjetivo e significa "ladrão" de coisas pequenas, ou "de pouquidades", como abona Antônio de Morais e Silva. 
Abelha maldósa,

Que nota o brinquêdo,

Imprime ao golôso 9

Seu ferrão n' hum dêdo.

Eis Amor dorido,

Que insoffrivel geme,

Sacóde a mãosinha,

E o áxe ${ }^{10}$ lhe expréme.

Rebrâma ${ }^{11}$, estrabóxa ${ }^{12}$,

E a Venus querida,

Pulando, lhe mostra

A rôxa ferida.

Do effeito espantado,

Pergunta-lhe, indaga,

Porque hum vil insecto

Motiva tal chaga!

“E admiras-te?” (A mãi

Risonha o aconselha:)

"Não és tu nos golpes

Igual a huma abelha?

Também és pequêna

Deidade infantil,

$\mathrm{E}$ os farpões, que lanças,

Golpêão cem mil”.

9 Golôso: grafia antiga de "guloso".

10 Axe: pequeno ferimento; dodói. Era termo infantil e afetivo em Portugal.

11 Rebrama: brama com intensidade.

12 Estrabóxa: grafia antiga de "estrabucha", de "estrabuchar", variante de "estrebuchar". 


\section{Nossa tradução do Idílio XIX}

Direta do grego, nossa tradução do idílio não se baseia na tradução latina, mas procura, como ela, emulá-lo em português, segundo o conceito de que tradução é modalidade da imitação poética. Não nos preocupamos em verter cada palavra do idílio XIX, nem tampouco a ordem dos termos do original, pois esses aspectos resultam das particularidades da língua grega. Dada a diferença de propriedade e de estrutura entre uma língua e outra, a fidelidade às palavras e à ordem produziria efeito distinto do que ambas produzem em grego. Entendida não como somatória de elementos linguísticos, mas como totalidade coerente com o modelo, a nossa tradução se norteia por um "princípio de compensação". Como afirma Du Bellay (1913, p. 79): “[...] não terá mal realizado o seu dever o tradutor que, sem corromper o sentido de seu autor, se esforça em compensar de um lado o que ele não pode verter de boa graça de outro ${ }^{13}$ ".

O hexâmetro dactílico foi freqüentemente traduzido em língua portuguesa pelo decassílabo - desde Camões o verso heróico por excelência. Retomando essa tradição, Odorico Mendes (1928; 2008), por exemplo, traduz as epopéias homéricas com decassílabo. Como o decassílabo é verso mais curto do que o hexâmetro dactílico, a escolha obrigou Odorico Mendes a suprimir diversos termos do original. A recente tradução da Ilíada feita por Haroldo de Campos (2003) em versos alexandrinos foi bem sucedida, pois ele teve maior "margem de manobra" para verter o hexâmetro. Mas utilizar o alexandrino para traduzir um poema tão curto apagaria a leveza e a agilidade características do idílio XIX.

Assim, optamos pelo decassílabo para traduzir o idílio XIX de Teócrito não apenas porque, como o hexâmetro dactílico em grego, é o verso tradicionalmente utilizado pela épica vernácula, mas porque nos pareceu ser o verso mais apto para reproduzir a graça desse poema em português. Isso nos obrigou a sacrificar alguns termos, como, por exemplo, "ele mostrou a ferida" (vv. 5), mas isso não comprometeu o objetivo de traduzir o sentido da composição. Por fim, procuramos reconstituir a estrutura da composição, baseada em repetições e paralelismos, como, por exemplo, a simetria entre a reclamação de Eros a Afrodite (vv. 5-6) e a resposta final dada por ela ao filho (vv. 8). Eis o resultado:

13 " [...] le translateur n'a point mal fait son devoir, qui sans corrompre le sens de son auteur, ce qu'il n'a peu rendre d'assez bonne grâce en un endroit, s'efforce de le recompenser en l'autre". 


\section{KHPIOK $\Lambda$ EПTH $\Sigma$}

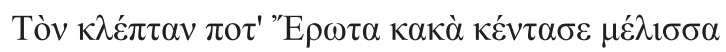

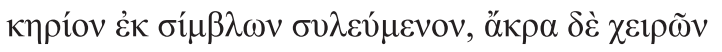

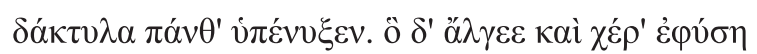

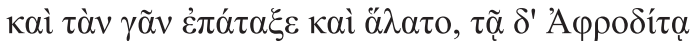

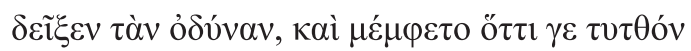

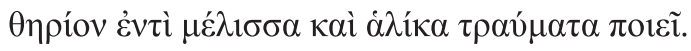

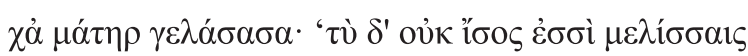

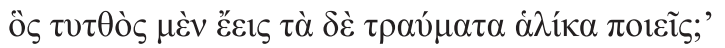

Eros Ferido ${ }^{14}$

Cruel abelha picou furtivo Eros quando roubava mel da sua colméia, ferroando as pontas todas dos seus dedos. De dor, ele sopra a mão e bate o pé, 5 reclamando a Afrodite que a abelha, por menor que ela seja, fira tanto. A mãe ri: "Tu não és igual à abelha? Por menor que tu sejas, feres tanto!"

\section{Referências}

ANDRADE, Adriano da Guerra. Dicionário de Pseudónimos e Iniciais de Escritores Portugueses. Lisboa: Biblioteca Nacional, 1999.

DU BELLAY, J. "Le Quatriesme Livre de l'Eneide de Vergile”, traduict en vers françoys. In: Oeuvres Complètes de Joachim du Bellay. Paris: Ed. Revue de la Renaissance, 1913. pp. 77-110. HOMERO. Odisséia, tradução de Odorico Mendes. Rio de Janeiro: Ed. Leite Ribeiro, 1928. . Ilíada, tradução de Odorico Mendes, prefácio e notas verso a verso de Sálvio Neinkötter. Cotia (SP): Ateliê Editorial / Campinas: Editora da Unicamp, 2008.

. Iliada, tradução de Haroldo de Campos, introdução e organização de Trajano Vieira. São Paulo: Arx, Volume I, 2003; Volume II, 2002.

LIMA, R. C. "Um Idílio Traduzido para o Latim do Renascimento: Critérios Utilizados na Época e Propostas de Tradução Poética”. In: Cadernos de Literatura em Tradução, 11, 2010. pp. 61-70.

RODRIGUES, N. S. Traduções Portuguesas de Teócrito, prefácio Victor Jabouille. Organização, introdução e notas de Nuno Simões Rodrigues. Lisboa: Ed. Universitária, 2000.

THEOCRITE. Les Bucoliques Grecs, introduction, traduction et notes par E. Chambry. Paris: Ed. Garnier Frères, Volume I, 1931.

THÉOCRITE. Bucoliques Grecs, texte, introduction et traduction par P.-E.Legrand. Paris: Les Belles Lettres, Volume I, 2002.

THEOCRITUS. Works, introduction, text and translation by A. S. F. Gow. London: Cambridge University Press, Volume I, 1971; Volume II, 1973.

VIRGÍLIO. Ecloges, edited by Robert Coleman. Cambridge: CUP, 1998.

14 Nossa tradução baseia-se na edição do texto grego por A. S. F. GOW (THEOCRITUS, 1971, p. 146). 